\title{
Alkanes ylide-vised to go near titanium
}

C6

high energy

materials

enable

resources

considered

'inert' to

be easily

activated and

transformed

g

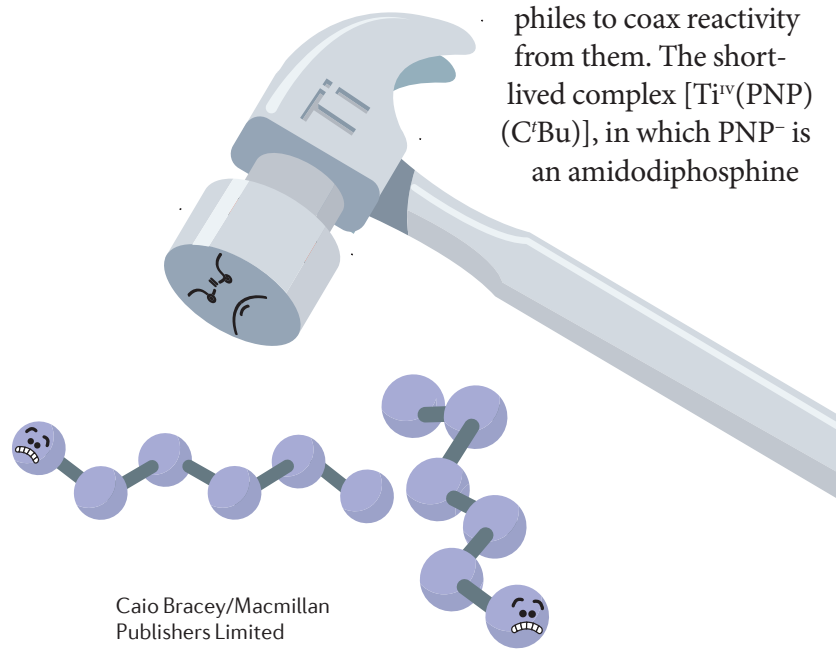

terdentate ligand, binds to cyclohexane in an almost thermoneutral process to afford the $\sigma$-complex $\left[\mathrm{Ti}^{\mathrm{rv}}(\mathrm{PNP})\left(\mathrm{C}^{t} \mathrm{Bu}\right)(\right.$ cyclohexane $\left.)\right]$. This species is adaptive, and modulation of the bond order between $\mathrm{Ti}$ and the carbyne ligand enables the latter to, in a stepwise fashion, snap off two $\mathrm{H}$ atoms from ligated cyclohexane, affording a cyclohexyl en route to the cyclohexene complex [ $\mathrm{Ti}^{\mathrm{II}}(\mathrm{PNP})$ $\left(\mathrm{CH}_{2}{ }^{t} \mathrm{Bu}\right)$ (cyclohexene)]. At this point, "we understood how the titanium alkylidyne could selectively dehydrogenate linear alkanes to terminal olefins, and cyclic alkanes to cyclic alkenes. However, we could not make the process cyclic or catalytic," Mindiola recalls. On releasing cyclohexene, the unsaturated $\mathrm{Ti}^{\mathrm{II}}$ complex requires stabilization, a problem that is solved by the triarylphosphorus methylene ylide $\left(\mathrm{H}_{2} \mathrm{C}\right) \mathrm{P}\left(\mathrm{C}_{12} \mathrm{H}_{8}\right) \mathrm{Ph}$ $\left(\mathrm{C}_{12} \mathrm{H}_{8}=\right.$ biphenyl-2,2'-diyl $)$. This species traps the $\mathrm{Ti}^{\mathrm{II}}$ complex to give the methylidene $\left[\mathrm{Ti}^{\mathrm{II}}(\mathrm{PNP})\left(\mathrm{CH}_{2}{ }^{t} \mathrm{Bu}\right)\right.$ $\left.\left(\mathrm{CH}_{2}\right)\right]$, which converts into the methyl tautomer $\left[\mathrm{Ti}^{\mathrm{II}}(\mathrm{PNP})\left(\mathrm{CH}^{\mathrm{t}} \mathrm{Bu}\right)\right.$ $\left(\mathrm{CH}_{3}\right)$ ]. This methyl tautomer can be independently prepared, along with 1-hexene and $\mathrm{P}\left(\mathrm{C}_{12} \mathrm{H}_{8}\right) \mathrm{Ph}$, from the ylide and $\left[\mathrm{Ti}^{\mathrm{II}}(\mathrm{PNP})\left(\mathrm{CH}_{2}{ }^{t} \mathrm{Bu}\right)\right.$ (1-hexene)]. In turn, the latter forms when $\left[\mathrm{Ti}^{\mathrm{iv}}(\mathrm{PNP})\left(\mathrm{CH}_{2}{ }^{t} \mathrm{Bu}\right)\left(\mathrm{CH}^{t} \mathrm{Bu}\right)\right]$ is treated with hexane, underscoring the selectivity of the system for terminal olefins.

That the methyl complex $\left[\mathrm{Ti}^{\mathrm{II}}(\mathrm{PNP})\left(\mathrm{CH}^{t} \mathrm{Bu}\right)\left(\mathrm{CH}_{3}\right)\right]$ is isolable hints to it being the resting state of the catalyst, a fact that is supported by calculations that indicate its

free energy to be $-53 \mathrm{kcal} \mathrm{mol}^{-1}$ relative to that of the carbyne. The reaction continues with the methyl complex undergoing slow hydrogen abstraction to give the transient $\sigma$-complex $\left[\mathrm{Ti}^{\mathrm{iv}}(\mathrm{PNP})\right.$ $\left.\left(\mathrm{C}^{\mathrm{t}} \mathrm{Bu}\right)\left(\mathrm{CH}_{4}\right)\right]\left(-26 \mathrm{kcal} \mathrm{mol}^{-1}\right)$.
Extrusion of $\mathrm{CH}_{4}$ closes the catalytic cycle, regenerating the reactive carbyne $\left[\mathrm{Ti}^{\mathrm{Iv}}(\mathrm{PNP})\left(\mathrm{C}^{t} \mathrm{Bu}\right)\right]\left(0 \mathrm{kcal} \mathrm{mol}^{-1}\right)$. The overall reaction involves conversion of an alkane and the phosphorus methylene ylide into an alkene, phosphine and methane.

The present dehydrogenation methodology is applicable to a range of cyclic and linear alkane substrates, with terminal alkenes being, gratifyingly, the sole products when the latter are used. Indeed, the Ti catalyst shows impressive selectivity, perhaps because it does not operate through a mechanism involving oxidative addition and/or hydrides. Yet, the strategy of Mindiola and co-workers has room for improvement in terms of its turnover numbers, which were only around 3 for most substrates tested. Moreover, the ylide $\left(\mathrm{H}_{2} \mathrm{C}\right) \mathrm{P}\left(\mathrm{C}_{12} \mathrm{H}_{8}\right) \mathrm{Ph}$ could not be substituted for the readily available reagent $\left(\mathrm{H}_{2} \mathrm{C}\right) \mathrm{PPh}_{3}$, which undergoes $\mathrm{P}-\mathrm{Ph}$ bond cleavage when in the presence of the Ti complexes - an illustration of just how reactive these alkane-activating compounds are. Indeed, "very high energy materials enable resources considered 'inert' to be easily activated and transformed," notes Mindiola. The group is now optimizing the approach, and, encouraged by ongoing theoretical and mechanistic studies, Mindiola foresees that turnover number could be improved by three orders of magnitude by simply switching to a different ylide or tuning the properties of the alkylidyne. "Ultimately, we want to partner this base metal catalyst with cheaper and more economically viable hydrogen acceptors," he says.

David Schilter

ORIGINAL ARTICLE Solowey, D. P. et al. A new and selective cycle for dehydrogenation of linear and cyclic alkanes under mild conditions using a base metal. Nat. Chem. http://dx.doi.org/10.1038/ nchem.2795 (2017) 